\title{
The science of belief: A progress report
}

\author{
Nicolas Porot $^{1} \quad$ Eric Mandelbaum ${ }^{2}$
}

${ }^{1}$ Philosophy, The Centre for Philosophical Psychology, University of Antwerp, Antwerp, Belgium

${ }^{2}$ Baruch College, The Graduate Center, CUNY, New York, New York

\section{Correspondence}

Nicolas Porot, Philosophy, The Centre for Philosophical Psychology, University of Antwerp, Antwerp, Belgium.

Email: nporot@gradcenter.cuny.edu

Funding information

NEH Fellowship, Grant/Award Number: FEL-257901-18

\begin{abstract}
The empirical study of belief is emerging at a rapid clip, uniting work from all corners of cognitive science. Reliance on belief in understanding and predicting behavior is widespread. Examples can be found, inter alia, in the placebo, attribution theory, theory of mind, and comparative psychological literatures. Research on belief also provides evidence for robust generalizations, including about how we fix, store, and change our beliefs. Evidence supports the existence of a Spinozan system of belief fixation: one that is automatic and independent of belief rejection. Independent research supports the existence of a system of fragmented belief storage: one that relies on large numbers of causally isolated, context-sensitive stores of belief in memory. Finally, empirical and observational data support at least two systems of belief change. One system adheres, mostly, to epistemological norms of updating; the other, the psychological immune system, functions to guard our most centrally held beliefs from potential inconsistency with newly formed beliefs. Refining our understanding of these systems can shed light on pressing real-world issues, such as how fake news, propaganda, and brainwashing exploit our psychology of belief, and how best to construct our modern informational world.

This article is categorized under:

Psychology $>$ Reasoning and Decision Making

Philosophy $>$ Knowledge and Belief

Philosophy $>$ Foundations of Cognitive Science
\end{abstract}

\section{KEYWORDS}

belief acquisition, belief change, fake news, functionalism, reasoning

\section{1 | INTRODUCTION}

Believing is like breathing: it happens so frequently we scarcely notice its occurrence. We avoid places that we believe ourselves to be unwelcome in, we arrive in places we believe our dates to be headed, and we vote for candidates that we think agree with our values. We can believe that god is female, or ungendered, or a very powerful otter, or does not exist. We can believe in god (i.e., put our faith in god), the goodness of humanity, or the calming eventuality of the heat death of the universe. But despite belief's ubiquity in our everyday view of the mind, one might wonder what work belief really does in our theories of the mind. Is belief merely a state in folk psychology, or does it have a place in cognitive science too? Is the notion of belief merely a stopgap to be used until more concrete notions arise from psychology, or neurobiology, or neurochemistry or physics? Here we review the data for the role belief plays in cognitive science. As in everyday life, though explicit talk of belief in cognitive science as such is scant, its tacit usage is widespread. Below, 
we describe how widely entrenched belief is in cognitive science. We then offer a snapshot of the current best science of belief. In the end, this article should establish that there is a robust science of belief, a thesis which will turn out to be surprising to many, even though the evidence for it has been hiding in plain sight.

We contend that this science is mature enough to supply concrete models of (some of) beliefs' functional role, specifically belief formation, belief storage, and belief updating. This entry offers an opinionated review of the empirical literature, both in the sense that we will not consider at length alternative models for the empirical work we cite, and because the models on offer are tendentious. But the perspective is far from unmotivated, as no other proposed framework explains as much of the data as the one we advocate, or as well.

The rest of this entry will be scant on traditional philosophical debates about belief. Yet this project is still valuable for philosophers interested in the nature of belief. Producing defensible empirical models of belief suggests that there really is a place for folk psychology in our science of the mind. The more precise the model, the more it allows theorists to argue about what features of the folk kind are core, and which more inessential, in cognitive scientific theorizing.

The model we end up offering is a variety of psychofunctionalism. Psychofunctionalism about belief aims to characterize belief in terms of the cognitive scientific generalizations belief enters into. Yet historically, actual proposals have been scant. Even the arch psychofunctionalists Fodor (1987) and Block (1980) never outlined proposals as to what generalizations actually subsumed belief. Their paradigm example of a law of belief was the practical syllogism. A defensible psychofunctionalism demands some specification of empirical models of belief. The robust scientific generalizations about belief that follow provide necessary detail to the bareboned psychofunctionalist account of belief.

\section{2 | BELIEF IN COGNITIVE SCIENCE: AN OVERVIEW}

\section{1 | Placebo effects and reward prediction error learning}

Pain is the body's response to suspected injury-it alerts the agent as to where, what type, and how much damage has occurred. But pain perception is not merely a bottom-up process: one's beliefs about pain greatly affect its phenomenology. Although general estimates of placebo effectiveness are hard to come by (domain specificity plays a role, as well as individual differences), placebo analgesia seems effective in $\sim^{1 / 3}$ of patients (Beecher, 1955; Ossipov, Dussor, \& Porreca, 2010). Complementarily, one can also find nocebo effects, where one's belief that they are about to experience pain causes subjects to experience pain even though they are subjected to non-painful stimuli (Colloca \& Benedetti, 2007). Culturally held beliefs about superficial features of objects affect pain modulation in predictable ways. For instance, the color of a placebo pill will change how users feel after ingestion, with red pills acting as stimulants, compared to blue ones (Jacobs \& Nordan, 1979). Similarly, price affects clinical outcomes: the more one pays for a placebo, the more effective it is (Tracey, 2010; Waber, Shiv, Carmon, \& Ariely, 2008).

A skeptic may argue that these effects are just response biases: perhaps taking a red placebo just makes people report that they feel higher levels of arousal, while they actually feel the same. However, this hypothesis leads to the prediction that lower-level machinery should remain unchanged in placebo cases. And placebos do affect low-level mechanisms, such as the circuitry involved in reward-prediction error learning (Gu et al., 2015). For example, when smokers (a) smoke cigarettes with nicotine and (b) believe they are smoking cigarettes that contain nicotine, they show elevated activity in the bilateral ventral striatum. That activity is indicative of the value signal at play in reward prediction error learning. Yet smokers show the same activation — and the same learning curve-if they smoked nicotine-free cigarettes that they believed contained nicotine. Placebos did not only cause false positives, but false negatives too: subjects who smoked real cigarettes that they falsely believed to be nicotine-free showed attenuated striatum activity. The reach of belief was widespread, affecting both the value signal and the reward prediction error signal separately (ibid p. 2541).

Talk of bilateral ventral striatum activity is only of interest here because it is indicative of dopaminergic pathways involved in reward prediction error learning. In other words, one's beliefs affect dopamine release in unconscious learning pathways. If beliefs can have computational consequences that far down, it is hard to say they are merely some useful fiction to be excised by a future cognitive science. On the contrary, beliefs seem to be a critical nexus around which the mind pivots.

There is nothing special about nicotine here. Similar results have been shown for cocaine (Kufahl et al., 2008) and alcohol (Gundersen, Specht, Grüner, Ersland, \& Hugdahl, 2008; van Holst, Clark, Veltman, van den Brink, \& Goudriaan, 2014). Shockingly, placebo effects have been shown to be even stronger than opioids. The synthetic opioid 
analgesic Remifentanil-a very fast short acting narcotic administered intravenously and used in the operating room for deep sedation-has what one might consider unmediated biological effects on behavior. Yet even these effects are swamped by one's beliefs about the drug-believing that one was getting the drug doubles its efficacy, while believing one was not ingesting the drug completely obliterates its effects, even as it is still being administered (Bingel et al., 2011). Remifentanil is no garden variety party drug-it is 200 times more potent than morphine and twice as potent as fentanyl (Wiklund \& Rosenbaum, 1997). And, while to our knowledge this is the only published effect (so far) of belief completely inhibiting an analgesic, there is plenty of evidence in the medical literature documenting analgesic placebo effects and pain nocebo effects (Watson, Power, Brown, El-Deredy, \& Jones, 2012).

All this is premised, of course, on the idea that researchers take belief to be the mental state doing the heavy lifting in explanation of placebo effects, rather than some other part of a participant's psychology. This claim should actually be fairly uncontroversial. It stems from a paradigmatic feature of the folk concept of belief: when you tell someone that $p$, all else equal, they form the belief that $p$. When researchers tell a participant that the treatment she is about to undergo will have a particular outcome, or they otherwise suggest as much (for example, by handing her a cigarette), they expect her to form the relevant belief. ${ }^{2}$

\section{2 | Attribution theory}

As mentioned in note 1, there are deep commonalities in explanations of placebo effects and attribution theory. In attribution processes-and in dissonance processes in general-what one believes has downstream effects on a host of other, seemingly unrelated processes. Attribution theory, broadly, is the study of how people attribute mental states to themselves and others. One could pick almost any misattribution of arousal study to show the power of belief, for they share a similar logic (Ross, 1977; Schachter \& Singer, 1962; Zanna \& Cooper, 1974). Here we focus on the effects of belief on insomnia because of how striking, and how useful, the datum is. Insomniac participants were asked to take a placebo before going to bed (Storms \& Nisbett, 1970). Subjects were told that the pill was to help researchers understand the relationship between bodily activity and dreams. The experimenters added that the pill would have side-effects, with half of subjects being told that the side effect would be arousing and the other half that it would be relaxing.

Of course, the pill, being a placebo, did none of these things. Nevertheless, the placebo had large, and ironic, effects on subjects' sleep. Those in the relaxing condition had even more trouble falling asleep than normal, while those in the arousal condition had their insomnia abate. The placebos caused the subjects to engage in (almost certainly unconscious) reasoning. For insomniacs, attempting to fall asleep provokes anxiety. When the insomniacs in the arousal condition entered their bedroom, they felt the normal anxiety they experience before going to sleep, but they now believed their anxiety was due to the pill they had just ingested. No longer having their anxiety of falling asleep as the attribution base for their arousal, the subjects were able to fall asleep much faster. On the contrary, those in the relaxing condition believed that they should now feel relaxed, as they thought they had taken a sedative. Consequently, they inferred that they were even more anxious than normal about falling asleep, and their insomnia correspondingly worsened.

The importance of the last datum is not that beliefs can change how long it'll take people to fall asleep. Instead, the crucial point is that the attribution process-an extremely pervasive phenomenon which occurs anytime we want to understand what we are feeling-is rife with beliefs and unconscious, instantaneous inferences from those beliefs (Bendaña \& Mandelbaum, 2021; Quilty-Dunn \& Mandelbaum, 2018b). As long as we have a science of attribution, we will need to quantify over beliefs.

\section{3 | Theory of mind}

One watches someone struggle with the pickle jar, then attributes to her the desire to eat pickles. This is an application of theory of mind (ToM), the ability to attribute intentional states to others. Of course, we can attribute beliefs to others, and so in that way, beliefs figure in ToM. But we must also possess beliefs in order to attribute them. ${ }^{3}$ Attributing a belief, desire, or other mental state to some agent is having a belief about the mental states of that agent. And while, strictly speaking, ToM discussions often advert to "attributing" or "thinking about" the states of others, it is not at all clear how one could attribute or think about those states without having some kind of occurrent belief about them.

A common test of ToM is the false belief task. Typical false belief tasks involve a "change-of-location" test. An experimenter places an object in a box or other opaque container, and a second experimenter moves the object to 
another opaque container, or out of view. What is manipulated is whether the first experimenter can be expected to perceive the location-change (for example, she might leave the room before the location-change, then return afterwards; or she might stay in the room, looking at the boxes). Several paradigms have been used to measure whether children, adults, and non-human animals respond differently in these two conditions, but they share a basic logic: if participants respond differently in the two conditions, it is because they manage to represent the first experimenter's cognitive state. In one condition they represent her as having a false belief, and in another, a true belief. ${ }^{4}$

Considerable debate surrounds whether false belief tasks track ToM, particularly in infants and non-human animals. One common objection, among many, is that they might be measuring attributions of behavioral or psychological features other than propositional attitudes. Consider variations of the false belief task run on chimpanzees, some of which manipulate whether a higher-ranking conspecific than the participant has visual access to a piece of food in a competitive setting. The chimps go after the food when the conspecific lacks visual access, and refrain when the conspecific has visual access. Many have objected that this task does not utilize chimp ToM per se, but instead relies on other kinds of thought about the conspecific. For example, the chimp might merely expect that the conspecific will go after ${ }^{5}$ the nearby food (Povinelli \& Vonk, 2003), or it might attribute the perceptual state of seeing the food to the conspecific, and then infer that it will go after the food (Andrews, 2017). But expectations and attributions are species of belief. Even on these meager interpretations, the best explanation of success on false belief tasks adverts to belief on the part of the ape, about a conspecific's going after or seeing the food. So even granting this style of objection, explaining false-belief task performance should move us to attribute belief to those that pass it. As it happens, this includes infants and several non-human animal species.

Belief is clearly pivotal to interpreting false-belief task results. But the lessons here are more general. First, belief seems to be so central to ToM that it is reasonable to think any test that is diagnostic of ToM will be diagnostic of the capacity for belief. ${ }^{6}$ For example, preverbal children and some non-human animals appear to pass anticipatory looking and violation of expectation tests, which do not rely on verbal responses. Independently of whether such tests really do measure a capacity for ToM, the success of non-linguistic organisms on these tasks dissociates linguistic competence from the capacity for belief. ${ }^{7}$

Belief's role in ToM solidifies its role the study of cognition generally. ToM is not some negligible, peripheral ability but instead appears to be a core part of many animals' cognitive and behavioral repertoires. ToM is widely thought to underpin much of social cognition; some have even theorized that lacking it is the main cause of autism (BaronCohen, 1997). In sum, ToM is central to (developmental, comparative, and clinical) psychology; thus, so is belief.

\section{4 | Belief in comparative cognition}

It might seem obvious that if human psychology adverts to beliefs, a psychology for at least some other animals will, too. But a long tradition in theorizing about animal cognition rejects the obvious. Descartes is often credited with the idea that non-human animals are "mere" automata, lacking mental substance. As such, animals could not have mental states of any kind, much less beliefs. More recently, some philosophers (Davidson, 1982, Stich, 1979, Bermúdez, 2008 ${ }^{8}$ ) have attempted to tie the capacity for believing to natural language competence. This strategy does not deny nonhuman animal mentality full-stop, but it keeps the spirit of the Cartesian view, at least as far as belief is concerned, by denying genuine non-human animal beliefs. And of course, thanks to Morgan's Cannon (Clatterbuck, 2016) and the very long reach of behaviorism in the study of animal learning and behavior, researchers studying animal cognition were long loathe to advert to belief-talk in their work.

In recent decades, the obvious has struck back. It is increasingly common for comparative psychologists, cognitive ethologists, and philosophers alike to describe animals as performing inferences (e.g., Tibbetts, Agudelo, Pandit, \& Riojas, 2019 [for paper wasps!]; Pepperberg, Gray, Mody, Cornero, \& Carey, 2019 [an African grey parrot]; Jensen, Alkan, Ferrera, \& Terrace, 2018 [macaques]; for an overview, see Porot, 2019), deciding between alternatives (Rosati \& Santos, 2016 [macaques]), planning for the future (Cheke \& Clayton, 2010 [several species]) possessing concepts (Howard, Avarguès-Weber, Garcia, Greentree, \& Dyer, 2019 [honeybees]), attributing false beliefs to others (Buttelmann et al., 2017; Krupenye et al., 2016 [great apes]), and engaging in metacognition (Smith, Couchman, \& Beran, 2014 [several species]). It is plausible that all of these states bring belief in their wakes.

It goes without saying that virtually every claim about an animal or species' possessing an intentional capacity has its detractors. For example, finding alternative explanations for false belief task success in chimpanzees has become a virtual subfield of its own in comparative cognition (e.g., Andrews, 2012, 2017; Lurz, 2015; Povinelli \& Vonk, 2003). 
Still, this represents a radical shift of the lines of debate. Moreover, this trend toward belief-talk does not reflect a mere change of rhetorical style among some researchers. For great apes generally, and especially chimpanzees, as well some monkey, dolphin, and avian species, non-intentional explanations of many behaviors have become increasingly, implausibly baroque.

The case of belief in non-human animals is an especially striking example of the centrality of belief to cognitive science. Decades of research and centuries of theorizing aimed to avoid talk of belief and related intentional states in nonhuman animals. Such avoidance was the raison d'être of behaviorist forays into human psychology—it was just patently clear to them that animals could not have these states and, since we are just animals, we should suppose that we do not have them either. Now, we can finally turn this logic on its head: if ever there were a domain of psychology where belief should turn out to be absent, it would be the study of non-human psychologies. That belief-talk has re-emerged in this field for even a few species nicely illustrates how integral belief is to cognitive science.

\section{5 | Belief in cognitive science: A midterm report}

The preceding should give the reader a taste of belief's ubiquity in cognitive science. From comparative psychology, to computational psychology, neuropsychiatry, social psychology, and developmental psychology, belief is ineliminablenot just from our daily folk practices, but from our everyday cognitive science. The four short subsections canvassed a relatively arbitrary bunch-we could have instead focused on entirely different fields, such as delusions, heuristics and biases, terror-management theory, dissonance theory, prospection, meta-cognitive fluency, or self-affirmation. We suspect this list continues on, for more areas than we are currently aware of.

As belief arises in so many areas of cognitive science, it deserves pride of place alongside such venerable stalwart concepts as memory, attention, perception, and mental representation. However, we have not yet shown the reader much evidence that there exists a science of belief, as opposed to the necessity of positing belief in scientific theorizing. We will now lay out some empirical results and generalizations of this nascent field, focusing on how beliefs are acquired, stored, and changed.

\section{3 | THE SCIENCE OF BELIEF: BELIEF ACQUISITION, STORAGE, CHANGE}

\section{1 | Belief acquisition}

Normative epistemological theories—-models of how one should believe-generally say to follow norms such as: apportion one's belief (/credence) to the evidence. If the evidence is equivocal, or non-existent, one should withhold judgment. This intuitive view is enshrined in a picture of belief acquisition called "The Cartesian Model" and it posits that one first entertains a proposition before accepting or rejecting it (Gilbert, 1991). Both acceptance and rejection are seen as active, effortful processes.

A competitor view, "The Spinozan Model," posits distinct systems of belief acquisition and rejection. On this view, acquisition is effortless, automatic, and mandatory. These ballistically acquired beliefs can then subsequently be endorsed or rejected. However, the processes underlying rejection are active and effortful: one has to have the proper available cognitive resources in order to focus on, and reject, the proposition after its acceptance. Thus, such processes can be short-circuited by inducing cognitive load. By contrast, the processes underlying acceptance are not affected by load, as they are reflexive and mandatory. ${ }^{9}$

Imagine you are presented with a sentence, along with some commentary as to whether it is true or false. Say the sentence is "Corn is the second major export of Angola,"10 and you are told that it is false. If you were presented with that sentence while under cognitive load, you will be apt to misremember it when later queried. You are likely to persist in thinking that it is true that corn is the second main export of Angola.

On the other hand, suppose you were presented with the sentence "Coal is the second main export of Guyana", and told that it is true. If you read this sentence while under cognitive load you would not be apt to misremember the sentence as false-you would persist in remembering it as true. That is, cognitive load results in misremembering falsehoods as truths, but does not result in misremembering truths as falsehoods. The Spinozan understands this difference as a difference not in encoding, but in rejecting. Both propositions-the one marked true and the one marked false-are encoded regardless of load. That is, both are automatically acquired. When you attempt to add 
the false tag (Asp \& Tranel, 2013), however, you sometimes fail because that takes effort, and so can be shortcircuited by load.

Instead of canvassing the totality of the explanatory work the Spinozan theory can do, ${ }^{11}$ we turn to a question that often arises: why are these states beliefs? One may wonder why the states so acquired should not count as some other, less committal state. One main reason is that the states in question are inferentially promiscuous-they serve as premises in downstream inferences. When someone acquires a proposition they know to be false while under load, they do not just merely parrot it back to an experimenter at some later point. Instead, the information becomes integrated in their overall web of belief and functions just as any other belief, generating actions and increasing one's knowledge base. $^{12}$

\section{2 | Belief storage}

How are beliefs stored in the mind? On the realist picture, where beliefs are relations to mental representations, these mental representations have to be stored and accessed. A tempting picture of what such storage looks like proceeds as follows: All the relevant representations reside in a single, holistically connected web in long-term memory. The web is designed to maximize coherence with both incoming evidence and standing beliefs. Since there is only a single memory store, any part of the total information stored can affect any other part.

Quine famously defended this "web of belief" picture of belief storage, where belief change transforms the topology of the entire store of beliefs (van Orman Quine \& Ullian, 1978). In the periphery of the web are perceptual beliefs, those most easily falsified and least inferentially integrated. Suppose you believe that you are wearing a green shirt. If given evidence that you are wearing a blue shirt (say you realize you are under a colored light), you can change this belief and almost no other beliefs would change with it. Beliefs that are more central are traditionally taken to be ones that are true in the broadest range of possible worlds. So your belief that modus ponens is valid, or that $2+2=4$, would be in the center of the web. Falsifying these beliefs would take enormous amounts of evidence, so the story goes, and would completely transform the shape of your web. The web is also thought to be efficient- there is one representation for each token belief, and this representation's location in the web indicates the totality of strength you have in the proposition expressed by the belief.

However, the web of belief view is descriptively inadequate; belief storage appears to be fragmented (Bendaña \& Mandelbaum, 2021; Elga \& Rayo, 2021). Fragmented belief storage contains distinct warehouses of information in memory, called fragments, which are, in the first instance, causally isolated from each other. Different fragments will often carry the same information-different tokens of the same type of belief-but have them associated with differing bodies of information. Fragmentation thus allows for both representational redundancy and a lack of epistemic closure. Representational redundancy is achieved by allowing different tokens of the same type of belief to appear in multiple data structures; lack of closure arises when the premises of an argument are housed in distinct fragments. For example, even if modus ponens is "built into the architecture" as a law of thought (Quilty-Dunn \& Mandelbaum, 2018b) lack of closure can be achieved if one believes $\mathrm{P}$ in one fragment and if $\mathrm{P}$ then $\mathrm{Q}$ in a separate one. The lack of interaction between the two premises would block one from inferring $\mathrm{Q}$.

Fragmentation solves a central puzzle in behavioral theorizing: how is it that people seem to abhor inconsistencies and yet harbor so many inconsistent beliefs? It allows for a belief system riddled with inconsistencies, as long as those inconsistencies are sequestered from one another in separate fragments. Each fragment is internally consistent and contains no redundant representations. But across fragments, consistency (and simplicity) is not maintained, and representational redundancy and inconsistency are expected. Thus, fragmentation can explain inconsistent beliefs while allowing our belief system to scaffold rational behavior. As long as only one fragment controls our behavior at any time, and as long as our fragments are more or less consistent, rational action will be the norm.

Fragmentation, in the form of functionally distinct memory stores, is already widely accepted in the study of memory: working memory, semantic memory, and episodic memory, as well as other stores more closely linked to perceptual systems. The fragmentation of belief expands this tradition and in doing so can make sense of a wide swath of disparate data. To give the reader a feel for it, we discuss just a few examples of representational redundancy and inconsistent belief.

Take the "wisdom of the crowds within" effect, where people are apt to tap into different bodies of information on the same topic with a mere change in temporal context (Vul \& Pashler, 2008). If asked the same question several times (e.g., "What percent of the world's roads are in India?") participants' mean responses tend to be closer to the truth than 
any of the individual responses, and the longer one waits between answers the better the averages get. ${ }^{13}$ The wisdom of the crowd within effect hinges on being able to tap into independent error. A web of belief view has all of one's beliefs connected, so it is hard to say how independent error could be achieved. Fragmentation achieves independent error as a matter of course. Fragments often store different bodies of information from one another. Statistical sampling from one individual at different times will function exactly like sampling across individuals at a time, modulo only differences between the distributions of stored information within and across individuals. Thus, the independent error needed to explain the wisdom of the crowds effect can be achieved within a single individual.

Fragmentation is designed to handle cases where changes in context cause different behaviors without any real informational change. And one finds such cases in reinforcement learning experiments. For example, previously extinguished associations rearise without any new learning (Bouton, 2004; Mandelbaum, 2015a). In these "spontaneous recovery" cases mere changes in temporal context-that is, letting time lapse-causes recovery of a previously putatively extinguished association. The fragmentationalist can explain these cases as ones where we have distinct bodies of information on the same topic, and which fragment is activated changes over time. Similarly, seemingly extinguished conditioned responses can spontaneously reappear in the presence of their unconditioned stimulus after a change in spatial context. For example, suppose that a rat put in a circular cage learns to associate a conditioned stimulus, such as a light, with an unconditioned stimulus, such as a shock. Further, suppose the association is then "extinguished" in a second, rectangular cage (because, e.g., the conditioned stimulus—such as a light-appears without the unconditioned stimulus-say a shock). A rat that is then put back in the first cage will sometimes show the "extinguished" behavior (Bouton \& Bolles, 1979). Importantly, it is not the fact that the rats learned the association in the first cage that matters here: If a rat both forms and extinguishes the association in the first cage, the association can be reinstated anyway when the rat is put in a second cage (Bouton \& Ricker, 1994).

Fragmentation can cover a wide range of other effects (see Bendaña \& Mandelbaum, 2021 for a fuller accounting), but to end we just want to stress how it is exactly the type of theory that would be needed for a Spinozan mind (Egan, 2008). If every proposition we encounter is initially believed, we will end up believing many contradictions. Producing rational action from a Spinozan mind demands fragmentation to account for our inconsistencies. This interlocking structure, of fragmented storage and Spinozan fixation, is exactly what one wants from a science of belief (or Psychofunctional theory of belief). The laws of belief should be, ideally, more than merely compatible with one another; they should be the natural complements of one another in a well-functioning cognitive system.

\section{3 | Belief change}

There are two robust and distinct research programs in belief change: one stemming from Bayesianism, and another from dissonance theory. Bayesian models of belief are, in general, approximations of near optimal belief updating, changing one's beliefs in accordance with changes in one's evidence. The breadth and scope of the Bayesianism, at least as a computational methodology, is unparalleled. Where Bayesianism works best is with beliefs that are held relatively dispassionately by the believer. But for updating the beliefs we most cherish, the ones one might use to express what one values, the story gets more complicated.

For beliefs one self-identifies with, rational updating - for example, apportioning and weighing evidence-is not the norm. People accept and reject information not to maintain epistemic coherence as much as to buttress their sense of self. For beliefs we self-identify with, belief updating is dictated by a psychological immune system, where counterattitudinal information is seen not just as any new evidence, but instead as a deep psychological threat. (Gilbert, Pinel, Wilson, Blumberg, \& Wheatley, 1998; Mandelbaum, 2019). The psychological immune system functions, first and foremost, to help us keep our most deeply held self-image. Just as our regular immune system does not react to any old bodily injury, but only more serious threats, so too the psychological immune system is not designed to ward off merely feeling bad, but instead kicks in when one encounters serious threats to one's self-image. The psychological immune system functions to protect our most core beliefs, the ones that make up our sense of who we are (such as the beliefs that one is a good person, a smart person, and a dependable person). Believing conclusions that challenge one's core beliefs puts one in a state of psychological distress. The psychological immune system remedies this by post-hoc rationalizing those conclusions away. ${ }^{14}$ Importantly, the existence of the psychological immune system does not exclude Bayesian belief change for beliefs that we do not self-identify with; rather, the two are distinct pieces of the psychology of belief. 
Examples of the immune system are striking. Imagine that you are a John F. Kennedy-assassination conspiracy theorist, one for whom the truth of the assassination is of the utmost importance. If you are shown evidence both for and against the conspiracy theory, you will not do the normatively rational thing and end up tempering your beliefs in the light of the fact that the evidence is equivocal; instead, you are likely to increase your antecedent belief in the conspiracy (McHoskey, 1995). That is, for people who care deeply about the JFK-assassination, receiving counterattitudinal information perversely causes people to increase their belief.

The workings of the immune system have nothing to do at all with conspiracy theories per se. It is just as apt to work off of anything that is central to one's self-conception. True believers of any stripe are apt to discount disconfirming evidence because of the crushing effects evidence would have on their way of life, and this holds whether we are looking at anti-Vaccers, or just anyone who has received a troubling medical diagnosis.

The immune system also works proactively. When it comes to information gathering, people tend to engage in selective exposure of information. They seek out information that is concordant with their beliefs, and avoid information that is discordant with them (Brock \& Balloun, 1967). They look for evidence that they are healthy, and that the mole on their back has not changed shape, or if it has, conclude that that is normal for moles, right?

\section{4 | Beliefs and the structure of thought: Implicit attitudes}

Traditional philosophical analyses have interpreted beliefs as relations to mental representations with truth-apt contents, that is, relations to sentences in languages of thought (Fodor, 1978, 1987). Realism about belief (and especially psychofunctionalism) would be well complemented if it could find empirical evidence that cohered with philosophical analyses showing that beliefs have language-like structure. Somewhat surprisingly, the Bayesian revolution has caused a resurgence in LoT models. The Bayesian "Probabilistic Language of Thought" interprets belief updating (/concept learning) as hypotheses in one's language of thought which get updated in line with the canons of probability theory (PLoT; Goodman, Tenenbaum, \& Gerstenberg, 2014). Yet the argument from PLoT is somewhat indirect-it posits the PLoT as the most likely structure available to house Bayesian updating. Insofar as one accepts a version of Bayesianism, one is committed to a LoT-like medium for Bayesian computations.

But one might also desire more direct evidence for the LoT in belief updating. To find some, we turn from computational cognitive psychology, to a science often less concerned with mechanism and the structure of thought: social psychology.

Consider implicit attitudes. ${ }^{15}$ An appealing way of characterizing the "attitudes" under consideration there is to say they are simply beliefs. ${ }^{16}$ If that is right, then implicit attitudes are relations to mental representations that express propositions. Mental representations that express propositions are structured; that is, they are not associative, just as the LoT hypothesis supposes. The idea that implicit attitudes have propositional structure is tendentious (cf. Brownstein, 2015, 2018). ${ }^{17}$ Mandelbaum (2016) and De Houwer, Van Dessel, and Moran (2020) have been the view's strongest proponents (though see the references in fn. xiv as a broader propositional consensus is emerging). The evidence for the propositional view is that manipulations of implicit attitudes proceed via logical, evidential manipulations sometimes by exploiting the syntactic structure of thought and logical machinery of thought (e.g., the cases in Mandelbaum, 2016) and other times by varying the strength of evidence one receives. ${ }^{18}$ For an example of the latter, single pieces of highly diagnostic information (like learning that someone you thought highly of is a criminal) can reverse one's implicit attitudes formed over many presentations (Mann \& Ferguson, 2015). ${ }^{19}$ Thus, the implicit attitudes literature lends evidence to the venerable philosophical conception of beliefs as propositionally structured strings of mental representations.

We've made a case for robust generalizations about the way that beliefs are acquired, stored, and changed. As mentioned in the introduction, such generalizations are congenial to a psychofunctionalist treatment of belief: they permit a level of specificity that such views have traditionally lacked. At the same time, these are not all the generalizations one might want over belief, and so there are more ways to build out the psychofunctional account. Others on the horizon include: attitude clarity (how one knows they hold a particular attitude, Petrocelli, Tormala, \& Rucker, 2007); attitude certainty (how one becomes certain that they hold the attitude they do, ibid); attitude activation (what makes it more likely that a given attitude will come to mind); and need for closure (what makes one need questions to be closed; Webster \& Kruglanski, 1994). In addition to these topics are related questions about individual differences in believers: what makes one more susceptible to believing pseudo-profound bullshit (Pennycook, Cheyne, Barr, Koehler, \& Fugelsang, 2015); what makes one more apt to reject any claims and "nay-say" (Knowles \& Condon, 1999); why some 
people are better than others at forming discerning beliefs (Pennycook \& Rand, 2019); why some people have greater preferences for consistency than others do (Cialdini, Trost, \& Newsom, 1995), and so on. For a discussion of these issues see Mandelbaum (in press).

\section{4 | FUTURE DIRECTIONS FOR THE EMPIRICAL STUDY OF BELIEF}

It is an exciting time for the cognitive science of belief. The study of belief is well-poised to fulfill the promise of cognitive science by having its many disparate areas of research come together and constrain each other's theorizing. As such, it is an antidote to psychological skeptics (Núñez et al., 2019). Philosophical questions about the nature of belief have become examinable through a wide range of empirical methods. To conclude, we briefly describe avenues for future research: as-of-yet unaddressed questions and promising recent work setting the stage for future research programs.

Earlier, we likened the ontological status of belief to other psychological entities such as memory, attention, and perception. But of course there is not one single mental faculty corresponding to any of these processes: there are working memory, long-term memory, iconic memory, echoic memory; there are endogenous and exogenous attentions; there is all manner of different types of perception. Perhaps one might expect that belief should fractionate into more specific kinds too.

Neil van Leeuwen has offered one means of expanding the ontology of belief-like attitudes $(2014,2017){ }^{20}$ Van Leeuwen argues many religious and supernatural "beliefs" are not factual beliefs, like the belief that Long Island Sound is polluted, but a kind of "secondary attitude," similar to imaginings, hypotheses, or assumptions for the sake of argument. Like other secondary attitudes, he claims, religious attitudes differ from bona fide beliefs as the former are highly context-sensitive. For example, members of the Vezo tribe in Madagascar speak about ancestors as if they had psychologically survived bodily decay when primed with a ritual context (burying a body in an ancestral tomb) but not when primed with a medical one (dying by malaria in a hospital) (Astuti \& Harris, 2008). Van Leeuwen claims that religious attitudes (and other secondary attitudes) do not have broad cognitive governance over other, non-religious attitudes. For example, Maya-speaking Itza claim humans sometimes transform into animals, yet they also do not worry that meat-eating is potentially cannibalistic (Atran, 2002, pp. 84-86). Finally, religious attitudes are not evidentially vulnerable: learning that a proposed doomsday has come and gone does not typically lead millennial cultists to leave the cult. If religious belief is not factual belief, then belief may need to be separated out into kinds, much like attention, memory, or perception. ${ }^{21}$

Another outstanding question is whether features-as understood on prototype theory-count as beliefs about categories. A vast psychological literature, calling on an array of experimental paradigms, has shown that categorization is easier for some members of a given category than for others (see, e.g., Hampton, 1995). If asked to name a pet, for example, dogs and cats are more likely to come to mind than ferrets, boas, or piranhas. The most common interpretations of these effects posit stored representations of features. For example, one's prototype of bird will have features such as +flies, +feathers, +small, and +cute. What is the status of these features? They do not seem to be mere associates (they are certainly not classically reinforced associates). But they also aren't generally interpreted as having internal structure. Nevertheless, it is unclear if that is a theoretical position taken or a mere typographical convenience. Accordingly, one might wonder if features function as beliefs about the things they are features of, such that having a prototype bird with a feature +flies is equivalent to believing that birds fly.

Other programs of research include metacognitive effects on belief. Our introspective access to our beliefs is poor, so we are forced to rely on metacognitive cues, such as fluency (Alter \& Oppenheimer, 2009). One question ripe for exploration is the extent to which fluent access serves as a cue for what one believes. Other questions involve the extent to which people think they have introspective access of their beliefs, and what the exact boundaries of introspective access are.

A current hotbed of inquiry is the relationship between full and partial belief. Much recent formal work has focused on partial belief-credences-and their role in formal epistemological theories and Bayesian cognitive science. But to make Bayesian updating computationally tractable, there must either be some heuristic we use-such as sampling (Vul, Goodman, Griffiths, \& Tenenbaum, 2014)—to approximate Bayes. What these heuristics are and how broadly they can be used is an in-demand topic. Similarly, the relationship between these states and traditional notions of strength of beliefs is ripe for investigation. ${ }^{22}$ 
Of course, questions of belief acquisition, change, and storage are still open ones of active research-we are still just making in-roads into creating justifiable and testable models. That said, we are already beginning to see crossover from the cognitive science of belief to the real-world issues of fake news, brainwashing, and propaganda (Mandelbaum, in press; Mandelbaum \& Quilty-Dunn, 2015; Pennycook, Cannon, \& Rand, 2018; Pennycook \& Rand, 2019). Once we have begun to understand and operationalize belief, we can start using this notion to better understand how advertisers, politicians, social media, and news feeds prey on our evolutionarily ancient methods of forming and changing beliefs. Some of this work has already begun. Gordon Pennycook, Dave Rand, and colleagues have begun to examine how social media, fake news, and belief acquisition interact. Their work looks at variables such as how warning labels (fail to) affect uptake of fake headlines, and how multiple presentations of such headlines affect overall credence. ${ }^{23}$ So far, their work has supported Spinozan models (under the guise of "illusory truth" effects—see below).

There are many directions in which to take this research. Cognitive scientists can look at how interventions last over-time, and assess the strength of the "sleeper effect," by which we come to believe claims over time that we have already rejected as false (Kumkale \& Albarracín, 2004). They can come to better understand how immune system-based polarization works in social media. Work here has already begun: Bail et al. (2018) paid Republican Twitter users $\$ 11$ to follow a bot that retweeted left-leaning content for a month. At the end of it, users' political views had shifted rightward (rather than to the middle), even by comparison with a control group of Republican users that did not follow the bot. Finally, the "illusory truth" effect is an especially promising avenue for understanding fake news. Seeing a sentence twice can make people more likely to judge it true (Hasher, Goldstein, \& Toppino, 1977). This even occurs with sentences clearly labeled "False" (Fazio, Brashier, Payne, \& Marsh, 2015) and sentences that are very obviously false (Fazio et al., 2019; Pennycook et al., 2018). Disappointingly, this phenomenon has been observed for news headlines, too Pennycook et al., 2018 showed an illusory truth effect for fake news headlines; the effect occurred even when participants' rated the fake articles' believability as low, and it was not erased by labels indicating articles had been shown false by independent fact checkers.

Studies like the ones just described touch on a host of new research questions for the study of belief and society. Another pressing question at the intersection of the cognitive science of belief and how we should structure our society is: how much of the way we live our everyday life induces cognitive load? If cognitive load shuts down our rejection processes, then it is of the utmost import to know when we are under load. If it is just when we are doing cognitive activities as intense as counting backwards from 100 in intervals of 7, or writing an essay, then load will be a relatively rare occurrence. If, on the other hand, load is conveyed through much lighter manipulations-say, scrolling through one's phone or watching cable news-then our understanding of our modern informational environment will differ greatly (Mandelbaum \& Quilty-Dunn, 2015). If load can be induced through light manipulations, then propaganda will be far more efficacious than we previously thought. The new science of belief thus holds promise to illuminate questions not just about the architecture of the mind, but of how best to construct our modern informational world.

\section{5 | CONCLUSION}

The philosophical community has generally treated belief as if it were a mere façon de parler. ${ }^{24}$ At best, it has been thought of as a prediction mechanism that somehow generates correct predictions; at worst, it's been thought to be a vacuous reification. Here instead of arguing about whether a science of belief is possible, we have detailed what the current state of the art is, providing a progress report on a field that is flourishing even if the practitioners of it do not always even know that it exists. As such the study of belief is one of the burgeoning fields of a maturing cognitive science.

\section{ACKNOWLEDGMENTS}

The authors thank Joseph Bendaña, Bennett Foddy, Dan Harris, Marc Porot and Jake Quilty-Dunn for helpful discussions.

\section{CONFLICT OF INTEREST}

The authors have declared no conflicts of interest for this article.

\section{AUTHOR CONTRIBUTIONS}

Eric Mandelbaum: Conceptualization; writing-original draft; writing-review and editing. 


\section{ORCID}

Eric Mandelbaum (D) https://orcid.org/0000-0002-0624-7763

\section{ENDNOTES}

This datum is reminiscent of the effort justification in dissonance theory (Quilty-Dunn \& Mandelbaum, 2018a). There, effort serves as a proxy for preference: the more effort one puts in, the more one infers they like the activity that demanded the effort; here cost stands as a proxy for effectiveness.

${ }^{2}$ It only strengthens the case here to observe that this platitude about testimony and belief is widely accepted outside of placebo research. It reinforces what is tacitly assumed by the idea of a cognitive science of belief: that the folk psychological kind is at least somewhat continuous with the scientific one appealed to in placebo studies. Similar scientific reliance on the folk concept of belief crops up frequently in psychology, including in the cases we consider in the next three subsections.

${ }^{3}$ For the interpretationalist the morals here get a bit tricky as attributing a belief to others suffices for the other to have the belief full stop. So for interepretationalists, it is possible to have a situation where (say) you attribute a belief to me, but no one has ever attributed any beliefs to you, in which case you would not count as having beliefs even though you attribute them to others.

${ }^{4}$ Many paradigms have been implemented for these tests, on children, infants, and non-human animals: violation-ofexpectation tasks (e.g., Onishi \& Baillargeon, 2005), anticipatory-looking tasks (e.g., Clements \& Perner, 1994; Krupenye, Kano, Hirata, Call, \& Tomasello, 2016), “explicit” false-belief tests (e.g., Baron-Cohen, Leslie, \& Frith, 1985), and spontaneous helping tasks (Buttelmann, Buttelmann, Carpenter, Call, \& Tomasello, 2017; Buttelmann, Carpenter, \& Tomasello, 2009).

${ }^{5}$ The "go after" locution is mentalistic. Surprisingly, it is also the one Povinelli \& Vonk themselves use to describe the contents of the subordinate chimps' attributions (2003, p. 153).

${ }^{6}$ Ditto for mind perception, our ability to think of other people, animals, and objects as things that can feel, think, decide, on the one hand, or hurt, taste, and wonder, on the other (Gray, Gray, \& Wegner, 2007). It is plausible that folk concepts of planning, communication, and, especially, thought, are closely related to a folk concept of belief. Mind perception for these capacities, like ToM, relies on a folk concept of belief. And, as was the case for ToM, belief is the only means by which one can attribute such folk states. Mind "perception" just is the formation of beliefs about the presence of other minds.

${ }^{7}$ ToM research also supports the idea that the folk psychological kind of belief does not float free of the scientific kind at work in psychology. The kind at work in explaining how a chimpanzee or an infant passes a false belief task turns out to be continuous with the folk psychological kind.

${ }^{8}$ Strictly speaking, Bermúdez does not reject that animals may have beliefs: He think that natural language so changes the nature of the beliefs one can hold that non-human animals' beliefs are deeply different from ours in nature. For example, for Bermúdez animals cannot, even in principle, have thoughts about thoughts. This brings out a common problem known as chauvinism: how can we characterize belief such that a) they are properly characterized in humans and b) they can still apply to other possible intelligences (Block, 1980). Generally the problem is taken to be one for psychofunctionalism, but Bermudez brings out that it is also a problem for common-sense functionalism: if one thinks it is a platitude that one can have beliefs about beliefs (which surely seems platitudinous), then, if Bermudez is right, animals cannot have beliefs.

${ }^{9}$ Endorsement almost always drops out of these discussions, which is curious as much has been written about its dual, rejection (and denial has also seen its fair share of discussion, see Ripley, 2011). Endorsement, as we use it, is a state that goes beyond acceptance in making a content primed for conscious reasoning and verbal report. It is reasonable to suppose that the difficulty in saying anything at all probative about these two fields are the stumbling block to studying the (perhaps fecund) terrain of endorsement.

${ }^{10}$ This example, and that in the next paragraph, are based on stimuli in Gilbert, Krull, \& Malone, 1990.

${ }^{11}$ Asymmetries between truth and falsity in thought are legion, but the Spinozan theory can explain a much broader scope of phenomena including the confirmation bias, anchoring and adjustment (one believes the anchor to be correct), source-monitoring errors, self-affirmation, innuendo, and more. Since the Spinozan theory pays its way by the breadth of effects it can explain, these other data are of some import. For a fuller picture of the scope of the theory see (Mandelbaum, 2014, in press). 
${ }^{12}$ For extended discussions on how these states serve as premises in inferences see Mandelbaum, 2016; Quilty-Dunn \& Mandelbaum, 2018a; Bendaña \& Mandelbaum, 2021. Those papers also contain some other arguments for why these states appear to function as beliefs, for example, they are caused by perception, interact with motivational states to cause action, they are truth apt, and, most importantly, they appear to be the same states at play in other laws about belief.

${ }^{13}$ Waiting longer raises the probability of accessing a more completely independent body of information. In the interim subjects are not getting any new information on the topic as can be seen by the accuracy of their guesses: first guesses tend to be better than subsequent guesses regardless of the time between each guess. And each response is based on the participant's best guess at the time, rather than, for example, on their consulting Google or an almanac.

${ }^{14}$ Importantly, this is not merely a matter of "hot cognition." The mechanics of the updating are consistent with the computational theory of mind (CTM). In general, most rationalizing processes (such as dissonance reduction) are rationally reconstructable from the standpoint of CTM, even if the processes themselves aren't particularly rational.

${ }^{15}$ For a defense of implicit attitude research see Brownstein, Madva, \& Gawronski, in press.

${ }^{16}$ Often enough, this is not explicit in the work of social psychologists (by contrast cognitive psychologists and neuroscientists, including many cited in this entry, use the word "belief" more readily). "Attitude," however, can be used to mean different things: preferences toward a content, a general valence, mere knowledge of a cultural stereotype (lacking any endorsement of the stereotype), or a belief. In the case of implicit attitudes, it has been suggested that implicit attitude tests measure knowledge of stereotypes, rather than belief in them. We note that in both cases, what is measured is a belief-either a belief that $p$, or a belief that the culture at large takes it that $p$.

${ }^{17} \mathrm{We}$, of course, do not think it is very tendentious at all (if those who work on attitudes want to excise structured representations from the mind, we wonder how they will reconstruct psycholinguistics). If any interventions in implicit attitudes work due to logical form, that is evidence that implicit attitudes have logical structure. Previously, the arguments from implicit attitudes to beliefs (e.g., Mandelbaum, 2016) went from the observation that attitudes are modulable due to their logical form to inferring that they are structured and then moving from the observation that they are structured to the identification of them with beliefs. Here we attempted to invert that logic and show that regardless of how the attitudes are modulated they seem to function as beliefs (and then infer from them being beliefs to them having structure). For other evidence of propositional structure of implicit attitudes see Mann \& Ferguson, 2015, 2017; Van Dessel, De Houwer, Gast, Smith, \& De Schryver, 2016; Cone, Mann, \& Ferguson, 2017; Kurdi \& Banaji, 2017; Mann, Kurdi, \& Banaji, 2019; Van Dessel, Ye, \& De Houwer, 2019; Kurdi \& Banaji, 2019; Hughes, Ye, Van Dessel, \& De Houwer, 2019.

${ }^{18}$ Other evidence offered for the propositional position is that propositional induction-telling people a piece of information-is a much stronger method of attitude acquisition than repeated associative exposure (see, for example, Kurdi \& Banaji, 2019).

${ }^{19}$ Admittedly, effects of these manipulations have not been shown to persist in the long term (Lai et al., 2016) but some have at least shown durability of $48 \mathrm{hr}$ (Mann \& Ferguson 2017).

${ }^{20}$ Though not the first one: some have argued, for example, that many of the states that look to be beliefs are in fact a different ontological kind: "aliefs" (Gendler, 2008). For Gendler, aliefs are associatively structured, and like irrational beliefs in that they will not update in normatively respectable ways. However, this view faces some serious difficulties (Mandelbaum, 2013). Relatedly, a distinction between tacit and standing beliefs has been adumbrated in many places. One problem (of many) for dispositionalist accounts of belief is the difficulty in distinguishing these two different kinds of belief (the psychofunctionalist posits that one only stores representations for standing, not tacit, beliefs, Quilty-Dunn \& Mandelbaum, 2018a).

${ }^{21} \mathrm{~A}$ problem for Van Leeuwen style accounts is that factual beliefs also seem to have problems updating (see, e.g., Anderson, 1983; Mandelbaum, 2019). The question of whether man-made global warming exists is a factual question, and one that leads to a factual belief, yet the updating of it is still stubbornly recalcitrant in the face of evidence. Part of the problem for Van Leeuwen is that almost all beliefs exhibit some type of context sensitivity. If belief storage is fragmented, then context sensitivity/lack of broad cognitive governance is the rule, not an exception. Additionally, there is a robust literature on what happens to millennial cults post prophecy that lead them to increase belief in the cult (so it is not as if the belief does not have wide ranging consequences. See Festinger et al., 1956).

${ }^{22} \mathrm{~A}$ related question is whether we need both full beliefs at all, or whether credences can do the work of full belief (for a recent discussion arguing that we need both concepts, full and partial belief, see Weisberg, in press).

${ }^{23}$ See, for example, Pennycook et al., 2018; Fazio, Rand, \& Pennycook, 2019 
${ }^{24} \mathrm{We}$ think this is often tacit but widespread, although it is also made explicit at times (e.g., Dennett, 1991; Schwitzgebel, 2013)

\section{RELATED WIRES ARTICLES}

What Do Implicit Measures Measure?

\section{Further Reading}

Dowsett, E., Semmler, C., Bray, H., Ankeny, R. A., \& Chur-Hansen, A. (2018). Neutralising the meat paradox: Cognitive dissonance, gender, and eating animals. Appetite, 123, 280-288. https://doi.org/10.1016/j.appet.2018.01.005

Dretske, F. (2004). Knowing what you think vs. knowing that you think it. In R. Schantz (Ed.), The externalist challenge (pp. 389-400). Berlin: De Gruyter. https://doi.org/10.1515/9783110915273

Faude-Koivisto, T., Würz, D., \& Gollwitzer, P. M. (2009). Implementation intentions: The mental representations and cognitive procedures of IF-THEN planning. In W. Klein \& K. Markman (Eds.), The handbook of imagination and mental simulation (pp. 69-86). New York: Guilford. https://doi.org/10.4324/9780203809846

Fodor, J. A. (1983). The modularity of mind, Cambridge, MA: MIT Press.

Greenwald, A., \& Nosek, B. (2009). Attitudinal dissociation: What does it mean? In R. Petty, R. Fazio, \& P. Brinol (Eds.), Attitudes: Insights from the new implicit measures, New York: Psychology Press.

Gweon, H., Young, L., \& Saxe, R. R. (2011). Theory of mind for you, and for me: Behavioral and neural similarities and differences in thinking about beliefs of the self and other. Proceedings of the annual meeting of the cognitive science society, 33.

Hall, L., Johansson, P., \& Strandberg, T. (2012). Lifting the veil of morality: Choice blindness and attitude reversals on a self-transforming survey. PLoS One, 7(9), e45457. https://doi.org/10.1371/journal.pone.0045457

Hawthorne, J., Rothschild, D., \& Spectre, L. (2016). Belief is weak. Philosophical Studies, 173(5), 1393-1404. https://doi.org/10.1007/s11098015-0553-7

Lange, M. (2002). Who's afraid of ceteris-paribus Laws? Or: How I learned to stop worrying and love them. In J. Earman, C. Glymour, \& S. Mitchell (Eds.), Ceterus Paribus Laws. Dordrecht: Springer.

Lewis, D. (1972). Psychophysical and theoretical identifications. Australasian Journal of Philosophy, 50(3), 249-258. https://doi.org/10.1080/ 00048407212341301

Lewis, D. (1980). Mad pain and Martian pain. In N. Block (Ed.), Readings in the philosophy of psychology (pp. 216-222). Cambridge, MA: Harvard University Press.

Lieder, F., \& Griffiths, T. L. (2019). Resource-rational analysis: Understanding human cognition as the optimal use of limited computational resources. Behavioral and Brain Sciences, 43, 1-85. https://doi.org/10.1017/S0140525X1900061X

Lycan, W. (1986). Tacit belief. In R. Bogdan (Ed.), Belief: Form, Content, and Function, New York: Oxford University Press.

Lycan, W. (2008). Phenomenal intentionalities. American Philosophical Quarterly, 45(3), 233-252.

Mandelbaum, E. (2015b). The automatic and the ballistic: Modularity beyond perceptual processes. Philosophical Psychology, 28(8), 11471156. https://doi.org/10.1080/09515089.2014.950217

Mandelbaum, E. (2018). Seeing and conceptualizing: Modularity and the shallow contents of perception. Philosophy and Phenomenological Research, 97(2), 267-283. https://doi.org/10.1111/phpr.12368

Marcus, G. F., \& Davis, E. (2013). How robust are probabilistic models of higher-level cognition? Psychological Science, 24(12), 2351-2360. https://doi.org/10.1177/0956797613495418

Ninan, D. (2016). What is the problem of de se attitudes? In M. Garcia-Carpintero \& S. Torre (Eds.), About oneself: De se attitudes and communication (pp. 86-120). Oxford: Oxford University Press. https://doi.org/10.1093/acprof:oso/9780198713265.001.0001

Ritchie, K. (2016). Can semantics guide ontology? Australasian Journal of Philosophy, 94(1), 24-41. https://doi.org/10.1080/00048402.2015. 1045912

Ross, L., Lepper, M. R., \& Hubbard, M. (1975). Perseverance in self-perception and social perception: Biased attributional processes in the debriefing paradigm. Journal of Personality and Social Psychology, 32(5), 880-892. https://doi.org/10.1037//0022-3514.32.5.880

Shea, N. (2019). Functionalist interrelations amongst human psychological states inter se, ditto for martians. In J. Smortchkova, K. Dolega, \& T. Schlicht (Eds.), What are mental representations? Oxford: Oxford University Press.

Stewart, B., \& Payne, B. (2008). Bringing automatic stereotyping under control: Implementation intentions as efficient means of thought control. Personality and Social Psychology Bulletin, 34(10), 1332-1345. https://doi.org/10.1177/0146167208321269

Stich, S. P. (1978). From folk psychology to cognitive science. Cambridge, England: MIT Press.

Taylor, E. G., \& Ahn, W. K. (2012). Causal imprinting in causal structure learning. Cognitive Psychology, 65(3), 381-413. https://doi.org/10. 1016/j.cogpsych.2012.07.001

Van Leeuwen, N. (2014). Religious credence is not factual belief. Cognition, 133(3), 698-715. https://doi.org/10.1016/j.cognition.2014.08.015

Van Leeuwen, N. (2017). Two paradigms for religious representation: The physicist and the playground (a reply to levy). Cognition, 164, 206211. https://doi.org/10.1016/j.cognition.2017.03.021

Wegner, D. M., \& Gilbert, D. T. (2000). Social psychology-The science of human experience). In H. Bless \& J. P. Forgas (Eds.), The message within: The role of subjective experience in social cognition and behavior. Philadelphia, PA: Psychology Press. 


\section{REFERENCES}

Alter, A. L., \& Oppenheimer, D. M. (2009). Uniting the tribes of fluency to form a metacognitive nation. Personality and Social Psychology Review, 13(3), 219-235. https://doi.org/10.1177/1088868309341564

Anderson, C. A. (1983). Abstract and concrete data in the perseverance of social theories: When weak data lead to unshakeable beliefs. Journal of Experimental Social Psychology, 19(2), 93-108. https://doi.org/10.1016/0022-1031(83)90031-8

Andrews, K. (2012). Do apes read minds?: Toward a new folk psychology, Cambridge, MA: MIT Press.

Andrews, K. (2017). Do chimpanzees reason about belief? In K. Andrews \& J. Beck (Eds.), The Routledge handbook of philosophy of animal minds (pp. 258-268). New York: Routledge. https://doi.org/10.4324/9781315742250-25

Asp, E., \& Tranel, D. (2013). False tagging theory. In D. T. Stuss \& R. T. Knight (Eds.), Principles of frontal lobe function (2nd ed., pp. 383416). New York: Oxford University Press. https://doi.org/10.1093/acprof:oso/9780195134971.001.0001

Astuti, R., \& Harris, P. (2008). Understanding mortality and the life of the ancestors in rural Madagascar. Cognitive Science: A Multidisciplinary Journal, 32(4), 713-740. https://doi.org/10.1080/03640210802066907

Atran, S. (2002). In gods we trust, New York: Oxford University Press.

Bail, C. A., Argyle, L. P., Brown, T. W., Bumpus, J. P., Chen, H., Hunzaker, M. F., \& Volfovsky, A. (2018). Exposure to opposing views on social media can increase political polarization. Proceedings of the National Academy of Sciences, 115(37), 9216-9221.

Baron-Cohen, S. (1997). Mindblindness: An essay on autism and theory of mind, Cambridge, MA: MIT Press.

Baron-Cohen, S., Leslie, A. M., \& Frith, U. (1985). Does the autistic child have a "theory of mind"? Cognition, 21(1), 37-46. https://doi.org/ 10.1016/0010-0277(85)90022-8

Beecher, H. K. (1955). The powerful placebo. Journal of the American Medical Association, 159(7), 1602-1606. https://doi.org/10.1001/jama. 1955.02960340022006

Bendaña, J., \& Mandelbaum, E. (2021). The fragmentation of belief. In D. Kindermann, C. Borgoni, \& A. Onofri (Eds.), The fragmentation of mind, Oxford: Oxford University Press.

Bermúdez, J. L. (2008). Thinking without words, Oxford: Oxford University Press.

Bingel, U., Wanigasekera, V., Wiech, K., Mhuircheartaigh, R. N., Lee, M. C., Ploner, M., \& Tracey, I. (2011). The effect of treatment expectation on drug efficacy: Imaging the analgesic benefit of the opioid remifentanil. Science Translational Medicine, 3(70), 70ra14. https://doi. org/10.1126/scitranslmed.3001244

Block, N. (1980). Troubles with functionalism. Readings in Philosophy of Psychology, 1, 268-305.

Bouton, M. E. (2004). Context and behavioral processes in extinction. Learning \& Memory, 11(5), 485-494. https://doi.org/10.1101/lm.78804

Bouton, M. E., \& Bolles, R. C. (1979). Role of conditioned contextual stimuli in reinstatement of extinguished fear. Journal of Experimental Psychology Animal Behavior Processes, 5, 368-378. https://doi.org/10.1037//0097-7403.5.4.368

Bouton, M. E., \& Ricker, S. T. (1994). Renewal of extinguished responding in a second context, renewal of extinguished responding in a second context. Animal Learning \& Behavior, 22, 317-324.

Brock, T. C., \& Balloun, J. L. (1967). Behavioral receptivity to dissonant information. Journal of Personality and Social Psychology, 6(4), 413-428.

Brownstein, M. (2015). Implicit Bias. In E. Zalta (Ed.), The Stanford encyclopedia of philosophy. Spring 2015 Edition. https://plato.stanford. edu/cgi-bin/encyclopedia/archinfo.cgi?entry=implicit-bias

Brownstein, M. (2018). The implicit mind: Cognitive architecture, the self, and ethics, New York: Oxford University Press. https://doi.org/10. 1093/oso/9780190633721.001.0001

Brownstein, M., Madva, A., \& Gawronski, B. (in press, 2019). What do implicit measures measure? Wiley Interdisciplinary Reviews: Cognitive Science, 10(5), e1501.

Buttelmann, D., Buttelmann, F., Carpenter, M., Call, J., \& Tomasello, M. (2017). Great apes distinguish true from false beliefs in an interactive helping task. PLoS ONE, 12(4), 1, e0173793-13. https://doi.org/10.1371/journal.pone.0173793

Buttelmann, D., Carpenter, M., \& Tomasello, M. (2009). Eighteen-month-old infants show false belief understanding in an active helping paradigm. Cognition, 112(2), 337-342. https://doi.org/10.1016/j.cognition.2009.05.006

Cheke, L. G., \& Clayton, N. S. (2010). Mental time travel in animals. WIREs Cognitive Science, 1(6), 915-930. https://doi.org/10.1002/wcs.59

Cialdini, R. B., Trost, M. R., \& Newsom, J. T. (1995). Preference for consistency: The development of a valid measure and the discovery of surprising behavioral implications. Journal of Personality and Social Psychology, 69(2), 318-328. https://doi.org/10.1037/0022-3514.69. 2.318

Clatterbuck, H. (2016). Darwin, Hume, Morgan, and the verae causae of psychology. Studies in History and Philosophy of Science Part C: Studies in History and Philosophy of Biological and Biomedical Sciences, 60, 1-14. https://doi.org/10.1016/j.shpsc.2016.09.002

Clements, W. A., \& Perner, J. (1994). Implicit understanding of belief. Cognitive Development, 9(4), 377-395. https://doi.org/10.1016/08852014(94)90012-4

Colloca, L., \& Benedetti, F. (2007). Nocebo hyperalgesia: How anxiety is turned into pain. Current Opinions in Anaesthesiology, 20(5), 435439. https://doi.org/10.1097/ACO.0b013e3282b972fb

Cone, J., Mann, T. C., \& Ferguson, M. J. (2017). Changing our implicit minds: How, when, and why implicit evaluations can be rapidly revised. In J. M. Olson (Ed.), Advances in experimental social psychology (Vol. 56, pp. 131-199). Cambridge, MA: Academic Press.

Davidson, D. (1982). Rational animals. Dialectica, 36, 317-328. https://doi.org/10.1111/j.1746-8361.1982.tb01546.x

De Houwer, J., Van Dessel, P., \& Moran, T. (2020). Attitudes beyond associations: On the role of propositional representations in stimulus evaluation. Advances in Experimental Social Psychology, 61, 127-183. 
Dennett, D. C. (1991). Real patterns. The Journal of Philosophy, 88(1), 27-51. https://doi.org/10.2307/2027085

Egan, A. (2008). Seeing and believing: Perception, belief formation and the divided mind. Philosophical Studies, 140(1), 47-63. https://doi. org/10.1007/s11098-008-9225-1

Elga, A., \& Rayo, A. (2021). Fragmentation and information access. In D. Kindermann, C. Borgoni, \& A. Onofri (Eds.), The fragmentation of mind, Oxford: Oxford University Press.

Fazio, L., Rand, D., \& Pennycook, G. (2019). Repetition increases perceived truth equally for plausible and implausible statements. Psychonomic Bulletin \& Review, 26, 1705-1710. https://doi.org/10.3758/s13423-019-01651-4

Fazio, L. K., Brashier, N. M., Payne, B. K., \& Marsh, E. J. (2015). Knowledge does not protect against illusory truth. Journal of Experimental Psychology: General, 144(5), 993-1002. https://doi.org/10.1037/xge0000098.supp

Festinger, L., Riecken, H., \& Schachter, S. (1956). When Prophecy Fails: A Social and Psychological Study of a Modern Group That Predicted the Destruction of the World. Minneapolis: University of Minnesota Press.

Fodor, J. A. (1978). Propositional attitudes. The Monist, 61(4), 501-523. https://doi.org/10.5840/monist197861444

Fodor, J. A. (1987). Psychosemantics: The problem of meaning in the philosophy of mind, Cambridge, MA: MIT Press.

Gendler, T. (2008). Alief and belief. The Journal of Philosophy, 105(10), 634-663. https://doi.org/10.5840/jphil20081051025

Gilbert, D. T. (1991). How mental systems believe. American Psychologist, 46(2), 107-119. https://doi.org/10.1037/0003-066X.46.2.107

Gilbert, D. T., Krull, D., \& Malone, M. (1990). Unbelieving the unbelievable: Some problems in the rejection of false information. Journal of Personality and Social Psychology, 59(4), 601-613. https://doi.org/10.1037/0022-3514.59.4.601

Gilbert, D. T., Pinel, E. C., Wilson, T. D., Blumberg, S. J., \& Wheatley, T. P. (1998). Immune neglect: A source of durability bias in affective forecasting. Journal of Personality and Social Psychology, 75(3), 617-638. https://doi.org/10.1037/0022-3514.75.3.617

Goodman, N. D., Tenenbaum, J. B., \& Gerstenberg, T. (2014). Concepts in a probabilistic language of thought. Center for Brains, Minds and Machines (CBMM).

Gray, H. M., Gray, K., \& Wegner, D. M. (2007). Dimensions of mind perception. Science, 315(5812), 619-619. https://doi.org/10.1126/science. 1134475

Gu, X., Lohrenz, T., Salas, R., Baldwin, P. R., Soltani, A., Kirk, U., ... Montague, P. R. (2015). Belief about nicotine selectively modulates value and reward prediction error signals in smokers. Proceedings of the National Academy of Sciences, 112(8), 2539-2544. https://doi.org/10. 1073/pnas.1416639112

Gundersen, H., Specht, K., Grüner, R., Ersland, L., \& Hugdahl, K. (2008). Separating the effects of alcohol and expectancy on brain activation: An fMRI working memory study. NeuroImage, 42(4), 1587-1596. https://doi.org/10.1016/j.neuroimage.2008.05.037

Hampton, J. A. (1995). Testing the prototype theory of concepts. Journal of Memory and Language, 34(5), 686-708. https://doi.org/10.1006/ jmla.1995.1031

Hasher, L., Goldstein, D., \& Toppino, T. (1977). Frequency and the conference of referential validity. Journal of Verbal Learning \& Verbal Behaviour, 16(1), 107-112. https://doi.org/10.1016/S0022-5371(77)80012-1

Howard, S., Avarguès-Weber, A., Garcia, J., Greentree, A. D., \& Dyer, A. D. (2019). Numerical ordering of zero in honeybees. Science, 360 (6393), 1124-1126. https://doi.org/10.1126/science.aar4975

Hughes, S., Ye, Y., Van Dessel, P., \& De Houwer, J. (2019). When people co-occur with good or bad events: Graded effects of relational qualifiers on evaluative conditioning. Personality and Social Psychology Bulletin, 45(2), 196-208. https://doi.org/10.1177/0146167218781340

Jacobs, K. W., \& Nordan, F. M. (1979). Classification of placebo drugs: Effect of color. Perceptual and Motor Skills, 49(2), 367-372. https:// doi.org/10.2466/pms.1979.49.2.367

Jensen, G., Alkan, Y., Ferrera, V. P., \& Terrace, H. S. (2018). Reward associations do not explain transitive inference performance in monkeys. Science Advances, 5(7), aaw2089. https://doi.org/10.7287/peerj.preprints.26889v1

Knowles, E. S., \& Condon, C. A. (1999). Why people say "yes": A dual-process theory of acquiescence. Journal of Personality and Social Psychology, 77(2), 379-386. https://doi.org/10.1037/0022-3514.77.2.379

Krupenye, C., Kano, F., Hirata, S., Call, J., \& Tomasello, M. (2016). Great apes anticipate that other individuals will act according to false beliefs. Science, 354(6308), 110-114. https://doi.org/10.1126/science.aaf8110

Kufahl, P., Li, Z., Risinger, R., Rainey, C., Piacentine, L., Wu, G., ... Li, S. J. (2008). Expectation modulates human brain responses to acute cocaine: A functional magnetic resonance imaging study. Biological Psychiatry, 63(2), 222-230. https://doi.org/10.1016/j.biopsych.2007. 03.021

Kumkale, G. T., \& Albarracín, D. (2004). The sleeper effect in persuasion: A meta-analytic review. Psychological Bulletin, 130(1), 143-172. https://doi.org/10.1037/0033-2909.130.1.143

Kurdi, B., \& Banaji, M. R. (2017). Repeated evaluative pairings and evaluative statements: How effectively do they shift implicit attitudes? Journal of Experimental Psychology: General, 146(2), 194-213. https://doi.org/10.1037/xge0000239

Kurdi, B., \& Banaji, M. R. (2019). Attitude change via repeated evaluative pairings versus evaluative statements: Shared and unique features. Journal of Personality and Social Psychology, 116(5), 681-703. https://doi.org/10.1037/pspa0000151

Lai, C. K., Skinner, A. L., Cooley, E., Murrar, S., Brauer, M., Devos, T., ... Simon, S. (2016). Reducing implicit racial preferences: II. Intervention effectiveness across time. Journal of Experimental Psychology: General, 145(8), 1001-1016. https://doi.org/10.1037/xge0000179

Lurz, R. W. (2015). Mindreading animals: The debate over what animals know about other minds. Cambridge, MA: MIT Press. https://doi.org/ 10.7551/mitpress/9780262016056.001.0001

Mandelbaum, E. (2013). Against alief. Philosophical Studies, 165(1), 197-211. https://doi.org/10.1007/s11098-012-9930-7

Mandelbaum, E. (2014). Thinking is believing. Inquiry, 57(1), 55-96. https://doi.org/10.1080/0020174X.2014.858417 
Mandelbaum, E. (2015a). Associationist theories of thought. In E. N. Zalta (Ed.), The Stanford encyclopedia of philosophy (Summer 2017 ed.). Retrieved from https://plato.stanford.edu/archives/sum2017/entries/associationist-thought/

Mandelbaum, E. (2016). Attitude, inference, association: On the propositional structure of implicit bias. Noûs, 50(3), 629-658. https://doi. org/10.1111/nous. 12089

Mandelbaum, E. (2019). Troubles with Bayesianism: An introduction to the psychological immune system. Mind \& Language, 34(2), 141157. https://doi.org/10.1111/mila.12205

Mandelbaum, E. (in press). A Psychofunctional theory of belief. New York, NY: Oxford University Press.

Mandelbaum, E., \& Quilty-Dunn, J. (2015). Believing without reason or: Why liberals shouldn't watch fox news. The Harvard Review of Philosophy, 22, 42-52. https://doi.org/10.5840/harvardreview2015226

Mann, T. C., \& Ferguson, M. J. (2015). Can we undo our first impressions? The role of reinterpretation in reversing implicit evaluations. Journal of Personality and Social Psychology, 108(6), 823-849. https://doi.org/10.1037/pspa0000021

Mann, T. C., \& Ferguson, M. J. (2017). Reversing implicit first impressions through reinterpretation after a two-day delay. Journal of Experimental Social Psychology, 68, 122-127. https://doi.org/10.1016/j.jesp.2016.06.004

Mann, T. C., Kurdi, B., \& Banaji, M. R. (2019). How effectively can implicit evaluations be updated? Using evaluative statements after aversive repeated evaluative pairings. Journal of Experimental Psychology: General. Advance Online Publication., 149, 1169-1192. https://doi. org/10.1037/xge0000701

McHoskey, J. W. (1995). Case closed? On the John F. Kennedy assassination: Biased assimilation of evidence and attitude polarization. Basic and Applied Social Psychology, 17(3), 395-409. https://doi.org/10.1207/s15324834basp1703_7

Núñez, R., Allen, M., Gao, R., Rigoli, C. M., Relaford-Doyle, J., \& Semenuks, A. (2019). What happened to cognitive science? Nature Human Behaviour, 3(8), 782-791. https://doi.org/10.1038/s41562-019-0626-2

Onishi, K. H., \& Baillargeon, R. (2005). Do 15-month-old infants understand false beliefs? Science, 308(5719), 255-258. https://doi.org/10. 1126/science.1107621

Ossipov, M. H., Dussor, G. O., \& Porreca, F. (2010). Central modulation of pain. Journal of Clinical Investigation, 120(11), 3779-3787. https:// doi.org/10.1172/JCI43766

Pennycook, G., Cannon, T. D., \& Rand, D. G. (2018). Prior exposure increases perceived accuracy of fake news. Journal of Experimental Psychology: General, 147(12), 1865-1880. https://doi.org/10.1037/xge0000465

Pennycook, G., Cheyne, J. A., Barr, N., Koehler, D. J., \& Fugelsang, J. A. (2015). On the reception and detection of pseudo-profound bullshit. Judgment and Decision Making, 10(6), 549-563.

Pennycook, G., \& Rand, D. G. (2019). Lazy, not biased: Susceptibility to partisan fake news is better explained by lack of reasoning than by motivated reasoning. Cognition, 188, 39-50. https://doi.org/10.1016/j.cognition.2018.06.011

Pepperberg, I. M., Gray, S. L., Mody, S., Cornero, F. M., \& Carey, S. (2019). Logical reasoning by a Grey parrot? A case study of the disjunctive syllogism. Behaviour, 156(5-8), 409-445. https://doi.org/10.1163/1568539x-00003528

Petrocelli, J. V., Tormala, Z. L., \& Rucker, D. D. (2007). Unpacking attitude certainty: Attitude clarity and attitude correctness. Journal of Personality and Social Psychology, 92(1), 30-41. https://doi.org/10.1037/0022-3514.92.1.30

Porot, N. J. (2019). Some non-human languages of thought. CUNY Academic Works. Retrieved from https://academicworks.cuny.edu/gc_ etds/3396.

Povinelli, D. J., \& Vonk, J. (2003). Chimpanzee minds: Suspiciously human? Trends in Cognitive Sciences, 7(4), 157-160. https://doi.org/10. 1016/s1364-6613(03)00053-6

Quilty-Dunn, J., \& Mandelbaum, E. (2018a). Against dispositionalism: Belief in cognitive science. Philosophical Studies, 175(9), 2353-2372. https://doi.org/10.1007/s11098-017-0962-x

Quilty-Dunn, J., \& Mandelbaum, E. (2018b). Inferential transitions. Australasian Journal of Philosophy, 96(3), 532-547. https://doi.org/10. $1080 / 00048402.2017 .1358754$

Ripley, D. (2011). Negation, denial, and rejection. Philosophy Compass, 6(9), 622-629. https://doi.org/10.1111/j.1747-9991.2011.00422.x

Rosati, A. G., \& Santos, L. R. (2016). Spontaneous metacognition in rhesus monkeys. Psychological Science, 27(9), 1181-1191. https://doi.org/ $10.1177 / 0956797616653737$

Ross, L. (1977). The intuitive psychologist and his shortcomings: Distortions in the attribution process. Advances in Experimental Social Psychology, 10, 173-220. https://doi.org/10.1016/S0065-2601(08)60357-3

Schachter, S., \& Singer, J. E. (1962). Cognitive, social, and physiological determinants of emotional state. Psychological Review, 69(5), 379399. https://doi.org/10.1037/h0046234

Schwitzgebel, E. (2013). A dispositional approach to attitudes: Thinking outside of the belief box. In N. Nottelmann (Ed.), New essays on belief (pp. 75-99). London: Palgrave Macmillan. https://doi.org/10.1057/9781137026521_5

Smith, J. D., Couchman, J. J., \& Beran, M. J. (2014). The highs and lows of theoretical interpretation in animal-metacognition research. In The Cognitive Neuroscience of Metacognition (pp. 87-111). Berlin, Heidelberg: Springer.https://doi.org/10.1007/978-3-642-45190-4_5

Stich, S. P. (1979). Do animals have beliefs? Australasian Journal of Philosophy, 57(1), 15-28. https://doi.org/10.1080/00048407912341011

Storms, M. D., \& Nisbett, R. E. (1970). Insomnia and the attribution process. Journal of Personality and Social Psychology, 16(2), 319-328. https://doi.org/10.1037/h0029835

Tibbetts, E., Agudelo, J., Pandit, S., \& Riojas, J. (2019). Transitive inference in Polistes paper wasps. Biology Letters, 15(5), 20190015. https:// doi.org/10.1098/rsbl.2019.0015 
Tracey, I. (2010). Getting the pain you expect: Mechanisms of placebo, nocebo and reappraisal effects in humans. Nature Medicine, 16(11), 1277-1283. https://doi.org/10.1038/nm.2229

Van Dessel, P., De Houwer, J., Gast, A., Smith, C. T., \& De Schryver, M. (2016). Instructing implicit processes: When instructions to approach or avoid influence implicit but not explicit evaluation. Journal of Experimental Social Psychology, 63, 1-9. https://doi.org/10.1016/j.jesp. 2015.11.002

Van Dessel, P., Ye, Y., \& De Houwer, J. (2019). Changing deep-rooted implicit evaluation in the blink of an eye: Negative verbal information shifts automatic liking of Gandhi. Social Psychological and Personality Science, 10(2), 266-273. https://doi.org/10.1177/1948550617752064

van Holst, R. J., Clark, L., Veltman, D. J., van den Brink, W., \& Goudriaan, A. E. (2014). Enhanced striatal responses during expectancy coding in alcohol dependence. Drug and Alcohol Dependence, 142, 204-208. https://doi.org/10.1016/j.drugalcdep.2014.06.019

van Orman Quine, W., \& Ullian, J. (1978). The web of belief. New York, NY: Random House.

Vul, E., Goodman, N., Griffiths, T. L., \& Tenenbaum, J. B. (2014). One and done? Optimal decisions from very few samples. Cognitive Science, 38(4), 599-637. https://doi.org/10.1111/cogs.12101

Vul, E., \& Pashler, H. (2008). Measuring the crowd within: Probabilistic representations within individuals. Psychological Science, 19(7), 645647. https://doi.org/10.1111/j.1467-9280.2008.02136.x

Waber, R. L., Shiv, B., Carmon, Z., \& Ariely, D. (2008). Commercial features of placebo and therapeutic. Journal of the American Medical Association, 299(9), 1016-1017. https://doi.org/10.1001/jama.299.9.1016

Watson, A., Power, A., Brown, C., El-Deredy, W., \& Jones, A. (2012). Placebo analgesia: Cognitive influences on therapeutic outcome. Arthritis Research \& Therapy, 14, 206. https://doi.org/10.1186/ar3783

Webster, D. M., \& Kruglanski, A. W. (1994). Individual differences in need for cognitive closure. Journal of Personality and Social Psychology, 67(6), 1049-1062. https://doi.org/10.1037//0022-3514.67.6.1049

Weisberg, J. (in press). Belief in psyontology. Philosophers' Imprint.

Wiklund, R. A., \& Rosenbaum, S. H. (1997). Anesthesiology (part one of two). New England Journal of Medicine, 337(17), 1215-1219. https:// doi.org/10.1056/nejm199710233371707

Zanna, M., \& Cooper, J. (1974). Dissonance and the pill: An attribution approach to studying the arousal properties of dissonance. Journal of Personality and Social Psychology, 29(5), 703-709. https://doi.org/10.1037/h0036651

How to cite this article: Porot N, Mandelbaum E. The science of belief: A progress report. WIREs Cogn Sci. 2020;e1539. https://doi.org/10.1002/wcs.1539 